\title{
Melting and Crystallization of Poly(vinylidene fluoride) in the Blend with Poly(methyl methacrylate) under High Pressure
}

\author{
Chitoshi NAKAFUKU and Munehisa YASUNIWA* \\ Faculty of Education, Kochi University, Kochi 780, Japan \\ *Faculty of Science, Fukuoka University, \\ Jonan-ku, Fukuoka 814-01, Japan
}

(Received September 29, 1986)

\begin{abstract}
Melting and crystallization of poly(vinylidene fluoride) $\left(\mathrm{PVF}_{2}\right)$ in the blend with poly(methyl methacrylate) (PMMA) was studied by differential thermal analysis (DTA) under high pressures up to $350 \mathrm{MPa}$. Characterization of the pressure-crystallized blend sample with different weight fractions of $\mathrm{PVF}_{2}$ between 1.0 and 0.5 was performed at atmospheric pressure by DTA, differential scanning calorimetry (DSC) and wide angle X-ray diffraction (WAXD) measurements. Pressure dependence of the melting temperature of form II of $\mathrm{PVF}_{2}$ in the blend between 1.0 and 0.6 of the weight fraction was almost the same (about $0.34 \mathrm{~K} \mathrm{MPa}^{-1}$ ). The WAXD patterns and thermal analysis of the blend show that form $\mathrm{I}$ of $\mathrm{PVF}_{2}$ crystallizes at lower pressure with increasing PMMA content in the sample. DTA and DSC at atmospheric pressure show that the high pressure crystallization of $\mathrm{PVF}_{2}$ in the blend with PMMA results in the formation of form I which melts at lower temperature than form II.
\end{abstract}

KEY WORDS Poly(vinylidene fluoride) / Poly(methyl methacrylate) / Blend / Phase Diagram / High Pressure / Crystallization / Compatibility / WAXD / DSC / DTA /

It is well known that in poly(vinylidene fluoride) $\left(\mathrm{PVF}_{2}\right)$, two different crystalline forms (form I and form II) are obtained according to the crystallization conditions. Form I is obtained by melt-crystallization under high pressure above $350 \mathrm{MPa}^{1-7}$ or drawing the form II film. The crystal structure of form $\mathrm{I}$ is orthorhombic and the molecular conformation is the TT type. Form I crystal melts at about $190^{\circ} \mathrm{C}$ at atmospheric pressure. Form II is obtained usually by melt-crystallization at atmospheric pressure. The crystal structure of form II is monoclinic $^{8}$ and the molecular conformation is the TGTG' $^{\prime}$ type. ${ }^{9}$ The melting temperature $T_{\mathrm{m}}$ of form II at atmospheric pressure is about $170^{\circ} \mathrm{C}$ and it changes with the content of head-to-tail linkage.

Several investigators have reported that
$\mathrm{PVF}_{2}$ and poly(methyl methacrylate) (PMMA) form a compatible mixture in the melt. ${ }^{10-13}$ The melting temperature of $\mathrm{PVF}_{2}$ decreases with decreasing $\mathrm{PVF}_{2}$ content in the blend. Nishi and Wang ${ }^{10}$ studied the melting and crystallization behavior of the blend and showed that the melting and crystallization temperatures strongly depend on both the composition and cooling rate. It is assumed that under high pressure, the compatibility of these two polymers increases in the melt and the increasing effect of PMMA molecule on the crystallization of $\mathrm{PVF}_{2}$ is expected.

In the present investigation, differential thermal analysis (DTÁ) of $\mathrm{PVF}_{2}$ and PMMA blends was performed under high pressures up to $350 \mathrm{MPa}$. The effect of pressure on the melting and crystallization of $\mathrm{PVF}_{2}$ in the blends was studied. In addition, character- 
ization of the pressure-crystallized blend sample was carried out by DTA, differential scanning calorimetry (DSC) and the wide angle X-ray diffraction (WAXD).

\section{EXPERIMENTAL}

The samples used in this study were as follows. A PVF 2 sample was a fine powder of Foraflon 1000 V.L.D. ${ }^{\circledR}$ (product of Puck Co. in France) supplied by Showa Denko Co. The number-average molecular weight $\bar{M}_{n}$ is $1.09 \times 10^{5}$ and the weight-average one $\bar{M}_{w}$ is $2.90 \times 10^{5}$ (supplier's data). The fluorine content of this sample is $59 \%$ in the catalog. PMMA with a molecular weight $9.33 \times 10^{4}$ was purchased from Scientific Polymer Products Inc. The mixed powder of $3 \mathrm{~g}$ of $\mathrm{PVF}_{2}$ and PMMA with the desired weight fraction was dissolved in $N, N$-dimethylformamide $\left(100 \mathrm{~cm}^{3}\right)$ at $30^{\circ} \mathrm{C}$ in a laboratory dish. The solvent was completely evaporated in a vacuum vessel after exposure to flowing air for 5 days in a glass box. By this procedure, a semitransparent film was obtained. To make the rod-like sample, the semitransparent film was stuffed in a glass tube and melt-crystallized in an oil bath at atmospheric pressure. Finally, a rod-like sample which is $1.8 \mathrm{~mm}$ in diameter and $11 \mathrm{~mm}$ in length was obtained.

The high pressure DTA apparatus used in this study was described previously. ${ }^{14}$ The rod like sample was cut $1.8 \mathrm{~mm}$ in length and drilled to make a hole $(0.8 \mathrm{~mm} \phi \times 0.9 \mathrm{~mm} \mathrm{l})$ in the center of the rod. The junction of a thermocouple was inserted in the hole and both the sample and the thermocouple were covered by epoxy resin according to the conventional method. ${ }^{14}$ The heating rate of the high pressure DTA was $6 \mathrm{~K} \mathrm{~min}^{-1}$ and the cooling rate was about $5 \mathrm{~K} \mathrm{~min}^{-1}$.

To make a pressure-crystallized blend sample, the rod of $11 \mathrm{~mm}$ in length was wrapped by aluminum foil and covered by epoxy resin. Its high pressure crystallization was performed in a high pressure vessel with sheathed heater on the outside. The sample was heated up to a temperature higher than its melting temperature by about $10 \mathrm{~K}$ at a desired pressure and then cooled at the same pressure. The heating and cooling rates in the crystallization process under high pressure of the sample were the same as that of the high pressure DTA.

WAXD measurements were performed on the rod like sample by a transmission method using a diffractometer. Nickel filtered $\mathrm{Cu}-K_{\alpha}$ radiation was used as an incident $\mathrm{X}$-ray beam. DSC measurements were performed with a Rigaku Denki low temperature thermal analyser. The heating rate of DSC was $5 \mathrm{~K} \mathrm{~min}^{-1}$ for all measurements.

\section{RESULTS AND DISCUSSION}

Figure 1 shows DSC melting traces of $\mathrm{PVF}_{2}-\mathrm{PMMA}$ blends with different weight fractions of $\mathrm{PVF}_{2}$ at atmospheric pressure. All the samples were melt-crystallized at atmospheric pressure before the melting experiments. The endothermic peaks are due to the melting of form II of $\mathrm{PVF}_{2}$. The melting peak becomes broader and the peak temperature decreases with decreasing $\mathrm{PVF}_{2}$ content. Peak temperatures of the DSC and DTA melting

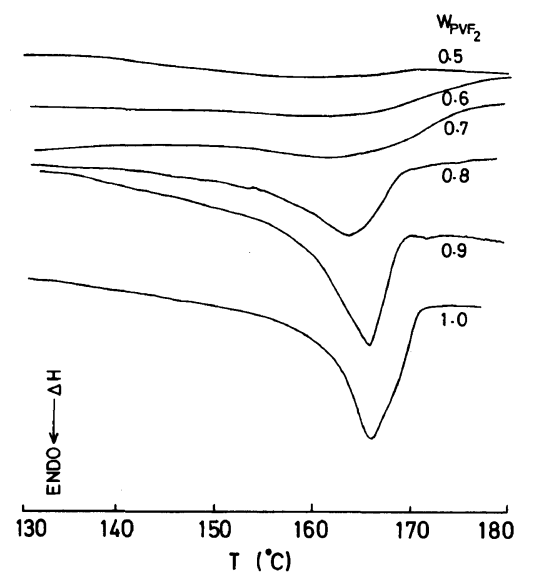

Figure 1. DSC traces of melting of blend samples crystallized at atmospheric pressure. $W_{\mathrm{PVF}_{2}}$ means the weight fraction of $\mathrm{PVF}_{2}$. 


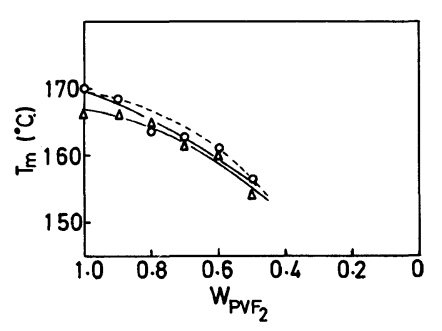

Figure 2. Change of melting temperature of $\mathrm{PVF}_{2}$ as a function of $W_{\mathrm{PVF}_{2}}$ by DTA (-O-) and DSC ( $\left.-\triangle-\right)$ in this work. ----, Nishi and Wang. ${ }^{10}$

trace were plotted against the weight fraction of $\mathrm{PVF}_{2}$ as shown in Figure 2. The data in this study agree with the data reported by Nishi and Wang ${ }^{10}$ though the sample of $\mathrm{PVF}_{2}$ used in this study is different from their sample (Kynar of Pennwalt Co.).

Melting and crystallization processes of pure $\mathrm{PVF}_{2}$ (KF polymer of Kureha Chemical Industry Co., Ltd.) under high pressure were studied in detail by Matsushige and Takemura. ${ }^{6}$ They determined the pressure dependence of $T_{\mathrm{m}}$ of folded chain crystals (FCC) of forms I and II and extended chain crystal (ECC) of form I obtained by high pressure crystallization above $350 \mathrm{MPa}$. They have shown that FCC of form II transformed to FCC of form I upon heating at pressures above $350 \mathrm{MPa}$ and to ECC of form I above $400 \mathrm{MPa}$.

High pressure DTA measurements were performed for the blend samples with the weight fraction of $\mathrm{PVF}_{2}\left(W_{\mathrm{PVF}_{2}}\right)$ between 1.0 and 0.5 . Figures 3(a) and (b) show the DTA melting traces at high pressure for pure $\mathrm{PVF}_{2}$ and the blend sample of $W_{\mathrm{PVF}_{2}}=0.8$. The melting peak shifts to the higher temperature with increasing pressure for both samples. At 156 $\mathrm{MPa}$ for pure $\mathrm{PVF}_{2}$, two peaks appear in the melting trace. It is supposed that transformation from form II to form I during heating process occurs at a heating rate as slow as $6 \mathrm{~K}$ $\min ^{-1}$ in comparison with $10 \mathrm{~K} \mathrm{~min}^{-1}$ by Matsushige and Takemura under this pressure, and that the high temperature peak is

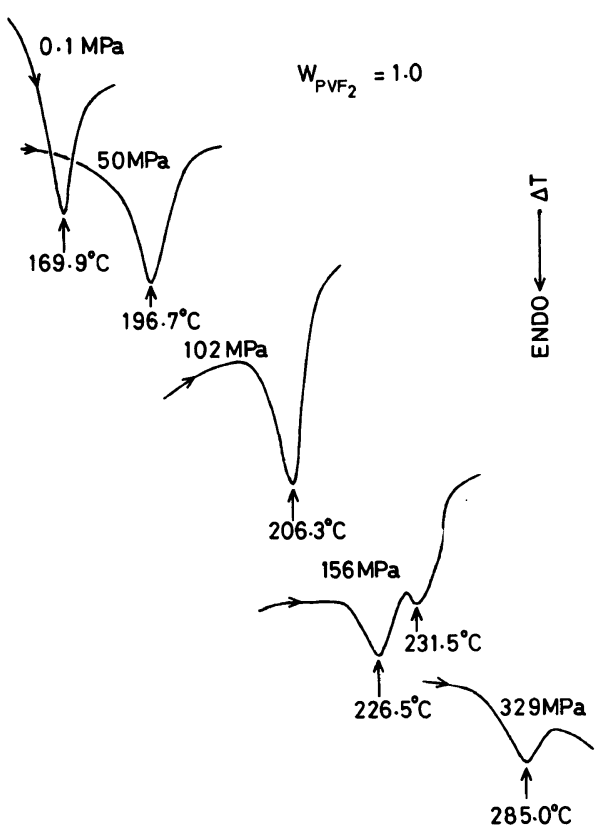

Figure 3(a). DTA traces of melting of pure $\mathrm{PVF}_{2}$ under high pressure.
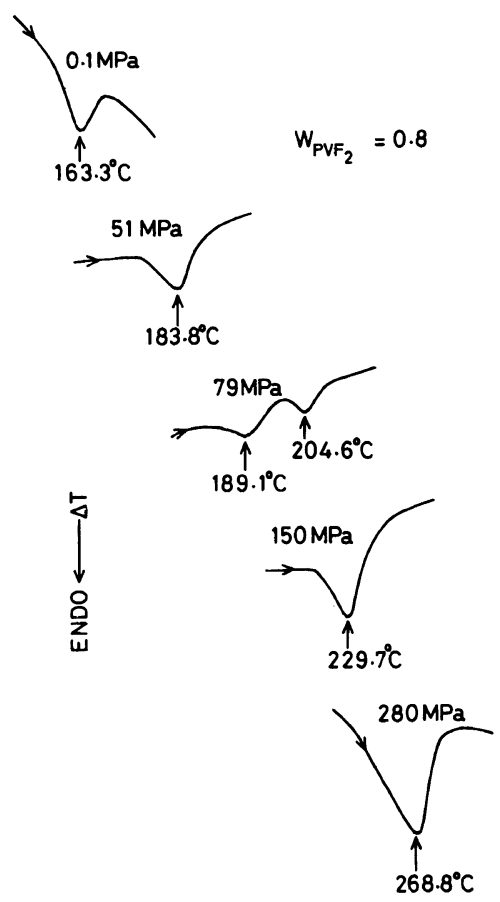

Figure 3(b). DTA traces of melting in a blend sample of $W_{\mathrm{PVF}_{2}}=0.8$ under high pressure. 


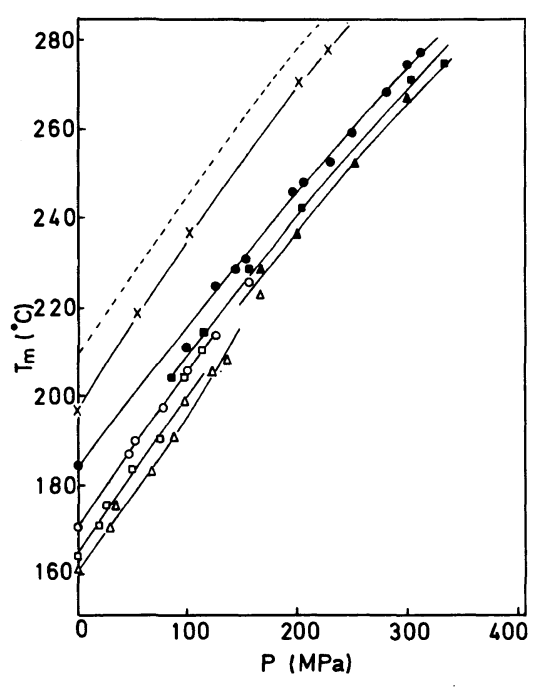

Figure 4. Pressure dependence of melting temperature of $\mathrm{PVF}_{2}$ in blend of melting temperature of $\mathrm{PVF}_{2}$ in blend samples. $\times, W_{\mathrm{PVF}_{2}}=1.0$ (form I, ECC);

$W_{\mathrm{PVF}_{2}}=1.0$ (form I, FCC); $\mathrm{O}, W_{\mathrm{PVF}_{2}}=1.0$ (form II); 口, $W_{\mathrm{PVF}_{2}}=0.8$ (form I); $\square, W_{\mathrm{PVF}_{2}}=0.8$ (form II); $\Delta, W_{\mathrm{PVF}_{2}}=0.6$ (form I); $\triangle, W_{\mathrm{PVF}_{2}}=0.6$ (form II); ,$--- \mathrm{ECC}$ of KF polymer. ${ }^{6}$

due to the melting of form. I. To confirm this fact, high pressure DTA was carried out at a heating rate of $6 \mathrm{~K} \mathrm{~min}^{-1}$ for $\mathrm{KF}$ polymer. The double peak also appeared in the DTA melting trace at $50 \mathrm{MPa}$ in the $\mathrm{KF}$ polymer in the heating rate of $6 \mathrm{~K} \mathrm{~min}^{-1}$, and the high temperature peak agreed with the melting point of form I at $50 \mathrm{MPa}$.

The transformation also occurs in the blend sample during heating under high pressure above about $70 \mathrm{MPa}$ in the heating rate of $6 \mathrm{~K} \mathrm{~min}^{-1}$ as shown in Figure 3(b); two peaks appeared between about 70 and $140 \mathrm{MPa}$. Above this critical pressure range for transformation at the same heating rate, only a high temperature peak due to the melting of form I appeared in the DTA trace. In the cooling, a single endothermic peak of crystallization was observed up to the maximum pressure range studied.

Figure 4 shows the pressure dependence of $T_{\mathrm{m}}$ of $\mathrm{PVF}_{2}$ in the blend sample. The transformation occurs between 90 and $150 \mathrm{MPa}$ at a
Table I. Comparison of the melting temperature $T_{m}$ of Foraflon by DSC and DTA and that of KF polymer'

\begin{tabular}{lccc}
\hline \multirow{1}{*}{ Polymer } & Form I, & Form II, & Form I, \\
& FCC & FCC & ECC \\
$T /{ }^{\circ} \mathrm{C}$ & $T /{ }^{\circ} \mathrm{C}$ & $T /{ }^{\circ} \mathrm{C}$ \\
\hline KF polymer $^{6}$ & 190 & 175 & 207 \\
Foraflon (DSC) & $\begin{array}{c}182.8 \\
(178)\end{array}$ & 166.0 & 193.2 \\
Foraflon (DTA) & 176.0 & 169.9 & 196.7 \\
\hline
\end{tabular}

Table II. Melting temperature $\left(T_{\mathrm{m}}\right)$ and pressure dependence $\left(\mathrm{d} T_{\mathrm{m}} / \mathrm{d} P\right)$ at $0.1 \mathrm{MPa}$ of ECC of form I and form II in the blend by DTA

\begin{tabular}{lcc}
\hline$W_{\mathrm{PVF}_{2}}$ & $T_{\mathrm{m}} /{ }^{\circ} \mathrm{C}$ & $\frac{\mathrm{d} T_{\mathrm{m}} / \mathrm{d} P}{\mathrm{~K} \mathrm{MPa}^{-1}}$ \\
\hline 1.0 (form I-ECC) & 196.7 & 0.41 \\
1.0 (form II) & 169.9 & 0.34 \\
0.9 & 168.5 & 0.33 \\
0.8 & 163.3 & 0.34 \\
0.7 & 162.6 & 0.35 \\
0.6 & 161.5 & 0.33 \\
0.5 & 155.8 & - \\
\hline
\end{tabular}

heating rate of $6 \mathrm{~K} \mathrm{~min}^{-1}$; the curve is not continuous in this critical pressure range. The curve shifts to the low temperature side with decreasing $\mathrm{PVF}_{2}$ content in the blend for both pressure range below $90 \mathrm{MPa}$ (form II melting) and above $150 \mathrm{MPa}$ (form I melting). The melting curve was obtained for all samples with different weight fractions between 1.0 and 0.5 of $\mathrm{PVF}_{2}$ in the blend.

In the DTA trace of melting at atmospheric pressure of pure $\mathrm{PVF}_{2}$ crystallized at $300 \mathrm{MPa}$, two peaks appeared, a sharp peak at $196.7^{\circ} \mathrm{C}$, and a broad peak around $176.0^{\circ} \mathrm{C}$. The peak temperature at the high temperature side in pure $\mathrm{PVF}_{2}$ crystallized at $300 \mathrm{MPa}$ is also shown as $(x)$ in Figure 4. From the comparison of the pressure dependence of $T_{\mathrm{m}}$ of the sample crystallized at $300 \mathrm{MPa}$ with that of ECC of KF polymer obtained by Matsushige and Takemura, it is assumed that the high temperature peak that appeared in the DTA trace of the sample crystallized at $300 \mathrm{MPa}$ is 


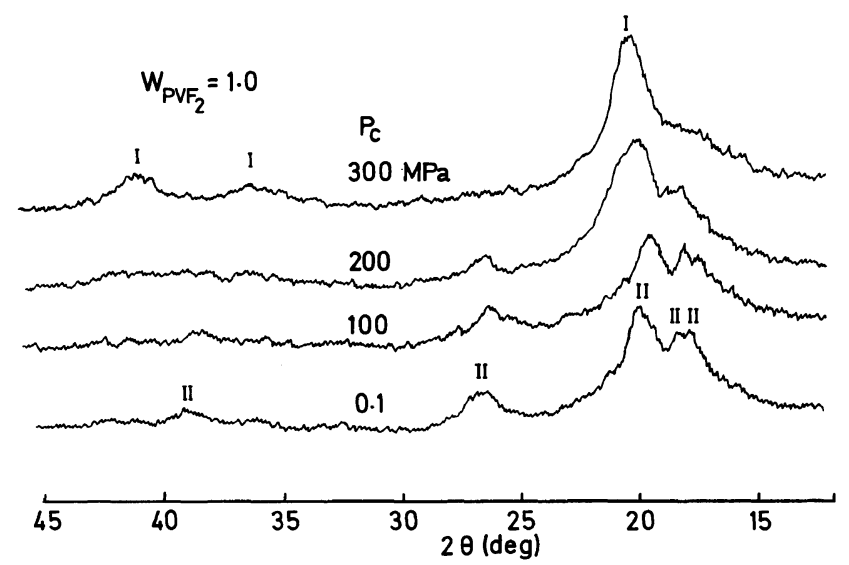

(a)

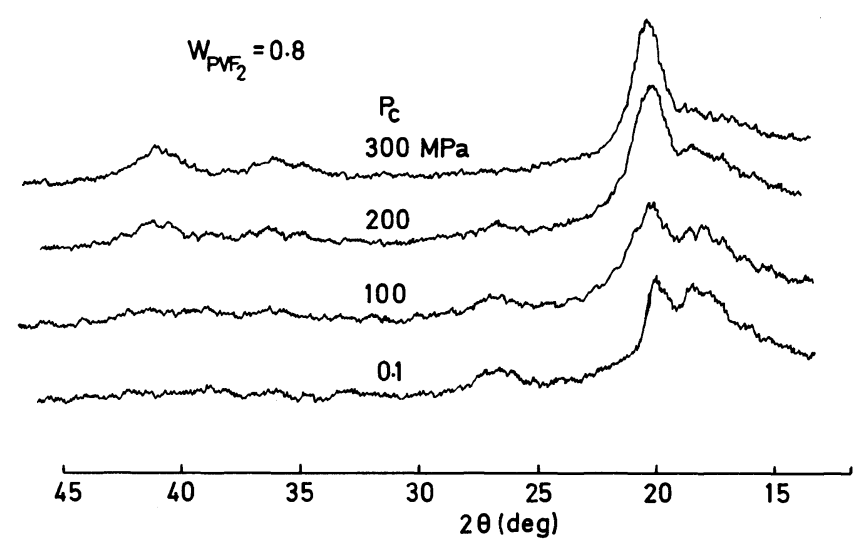

(b)

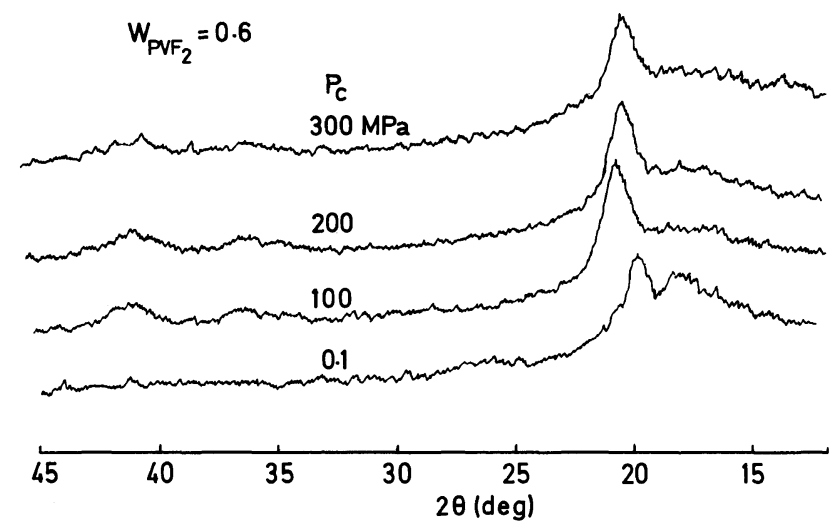

(c)

Figure 5. Wide angle $\mathrm{X}$-ray diffraction patterns of high pressure crystallized $\mathrm{PVF}_{2}$ in the blend. I and II indicate the diffraction peak from forms I and II. (a) $W_{\mathrm{PVF}_{2}}=1.0$. (b) $W_{\mathrm{PVF}_{2}}=0.8$. (c) $W_{\mathrm{PVF}_{2}}=0.6$. 
due to the melting of ECC. The $T_{\mathrm{m}}$ of FCC of form II and form I in Foraflon at atmospheric pressure is lower than that of form II and form $\mathrm{I}$ in KF polymer as shown in Table $\mathrm{I}$. Therefore, it is reasonable to assume that $T_{\mathrm{m}}$ of ECC of form I in Foraflon is also lower than that of ECC of form I in KF polymer. The pressure dependence of $T_{\mathrm{m}}$ at atmospheric pressure $\left(\mathrm{d} T_{\mathrm{m}} / \mathrm{d} P\right)$ for form II in the blend with different composition ratios was determined from the data below $90 \mathrm{MPa}$ using the least squares method. Table II lists the values of $T_{\mathrm{m}}$ and $\mathrm{d} T_{\mathrm{m}} / \mathrm{d} P$ at atmospheric pressure determined by DTA for pure PVF $_{2}$ and the blend. The value of $\mathrm{d} T_{\mathrm{m}} / \mathrm{d} P$ is almost constant, although $T_{\mathrm{m}}$ decreases with decreasing $\mathrm{PVF}_{2}$ content. In the case of $W_{\mathrm{PVF}_{2}}=0.5$, the melting peak in high pressure DTA was very broad and the value of $\mathrm{d} T_{\mathrm{m}} / \mathrm{d} P$ was not determined.

The pressure-crystallized blend sample was studied by WAXD to check the pressure effect on the formation of form I and form II crystal. Figures 5(a), (b), and (c) shows WAXD patterns of the blend crystallized under pressure. In the figure, the diffraction peaks around $18^{\circ}$, $20^{\circ}, 26^{\circ}$, and $38^{\circ}$ are due to form II and the peaks around $21^{\circ}, 36^{\circ}$, and $41^{\circ}$ are due to form I. It is clear.that the intensity of the diffraction peaks from form I increases and that of the peaks from form II decreases with increasing pressure. The WAXD pattern of the sample crystallized at $300 \mathrm{MPa}$ shows that most of the crystals in the sample is form I. In the blend with $W_{\mathrm{PVF}_{2}}=0.8$, the diffraction peaks from form I begin to appear at $200 \mathrm{MPa}$. In the blend of the lower $\mathrm{PVF}_{2}$ content, the diffraction peaks from form I appear at the lower crystallization pressure $P_{\mathrm{c}}$. The WAXD pattern of the sample crystallized at $100 \mathrm{MPa}$ on $W_{\mathrm{PVF}_{2}}=0.6$ shows that only form I crystallized.

The change in the content of form I and form II with pressure and the weight fraction of $\mathrm{PVF}_{2}$ obtained from WAXD measurement is summarized in Table III. It is clear from the table that form $\mathrm{I}$ of $\mathrm{PVF}_{2}$ crystallizes at lower
Table III. Dominant crystal form of $\mathrm{PVF}_{2}$ determined from the X-ray diffraction pattern in pressurecrystallized blend. Crystalline form at the left is dominant

\begin{tabular}{lccll}
\hline & \multicolumn{4}{c}{$P_{\mathrm{c}}$} \\
\cline { 2 - 5 }$W_{\mathrm{PVF}_{2}}$ & $300 / \mathrm{MPa}$ & $200 / \mathrm{MPa}$ & $100 / \mathrm{MPa}$ & $0.1 / \mathrm{MPa}$ \\
\hline & I & II, I & II & II \\
1.0 & I & I, II & II & II \\
0.9 & I & I, II & II, I & II \\
0.8 & I & I & II, I & II \\
0.7 & I & I & I & II \\
0.6 & I & I & I & II (I) \\
0.5 & & & & \\
\hline
\end{tabular}

pressure with increasing PMMA content in the blend. In $W_{\mathrm{PVF}_{2}}=0.5$, form $\mathrm{I}$ appears even in the crystallization at atmospheric pressure. Leonard et al. ${ }^{15}$ studied the formation of form I of $\mathrm{PVF}_{2}$ in the blend with PMMA at atmospheric pressure using infrared (IR) absorption method. They reported that the content of form I of $\mathrm{PVF}_{2}$ increases in blends, if the blend is quenched from the melt and then annealed in the temperature range between 330 and $390 \mathrm{~K}$.

Figure 6 shows the change in DSC melting traces at atmospheric pressure on the blend sample crystallized at $300 \mathrm{MPa}$. X-Ray diffraction for all the samples in this figure shows diffraction peaks from form I and no peaks from form II. In pure $\mathrm{PVF}_{2}$, three endothermic peaks appear in the trace. The peak at $193.2^{\circ} \mathrm{C}$ is ascribed to the melting of ECC of form I, and the other two peaks at 182.8 and $176.8^{\circ} \mathrm{C}$ are assigned to the melting of FCC of form I. The reason why two melting peaks of FCC form I appears is not clear. The melting peak for the pressure-crystallized blend sample is broad especially at lower content of $\mathrm{PVF}_{2}$ and the peak temperature is very low; in $W_{\mathrm{PVF}_{2}}=$ 0.9 , a single peak appears at $162^{\circ} \mathrm{C}$ and in $W_{\mathrm{PVF}_{2}}=0.8$, the peak temperature is $159^{\circ} \mathrm{C}$. It should be noted that the crystallization of $\mathrm{PVF}_{2}$ in the blend with PMMA under high pressure produces form I with lower melting temperature than form II obtained by melt- 


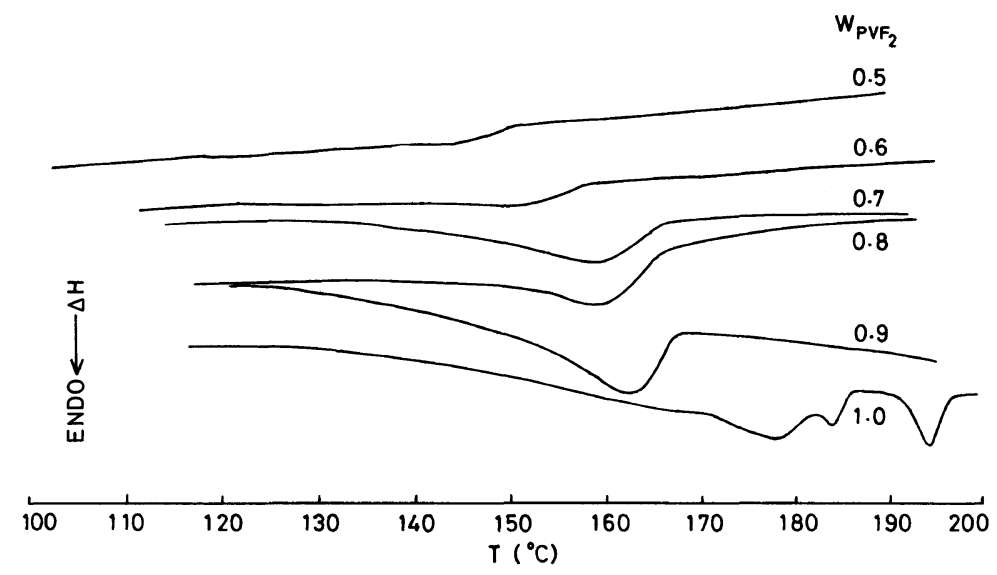

Figure 6. DSC traces of melting of $\mathrm{PVF}_{2}$ in blend crystallized under $300 \mathrm{MPa}$.

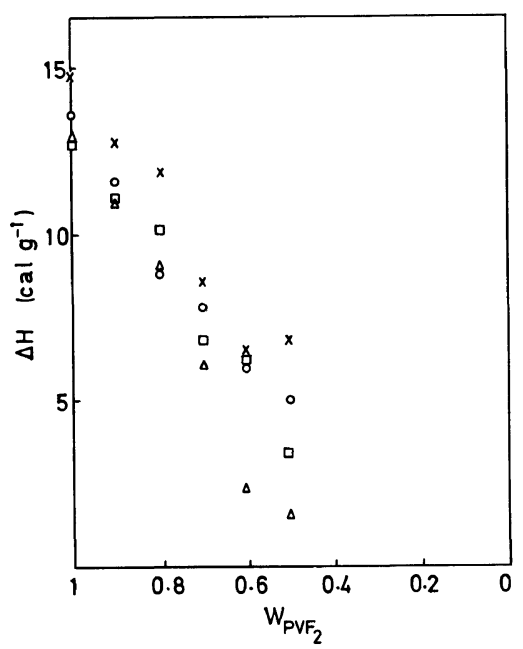

Figure 7. Weight fraction $\left(W_{\mathrm{PVF}_{2}}\right)$ dependence of heat of fusion $(\Delta H)$ of $\mathrm{PVF}_{2}$ in blend at various crystallization pressures $\left(P_{\mathrm{c}}\right) . \bigcirc, P_{\mathrm{c}}=0.1 \mathrm{MPa} ; \times, 100 \mathrm{MPa} ; \square$, $200 \mathrm{MPa} ; \triangle, 300 \mathrm{MPa}$.

crystallization at atmospheric pressure on pure $\mathrm{PVF}_{2}$.

Heat of fusion $(\Delta H)$ for the pressurecrystallized pure $\mathrm{PVF}_{2}$ and the blend was determined by DSC. Figure 7 shows the weight fraction dependence of the heat of fusion of the blend crystallized under high pressure. $\Delta H$ decreases with decreasing weight fraction of $\mathrm{PVF}_{2}$ and the decreasing rate is larger in the pressure-crystallized blend. At a crystallization pressure of $300 \mathrm{MPa}, \Delta H$ decreased to 1.6 $\mathrm{calg}^{-1}$ for the blend of $W_{\mathrm{PVF}_{2}}=0.5$ from 13 calg $^{-1}$ for $W_{\mathrm{PVF}_{2}}=1.0$. According to Nishi and Wang, ${ }^{10}$ the endothermic area in the DSC melting trace of $\mathrm{PVF}_{2}$ in the $\mathrm{PVF}_{2} / \mathrm{PMMA}$ blend decreases with decreasing $\mathrm{PVF}_{2}$ content more rapidly than the decreasing rate determined by assuming no interaction between the component. The two polymers form a compatible mixture in the melt. The drastic decrease of $\Delta H$ with decreasing $\mathrm{PVF}_{2}$ content in the high pressure crystallized blend in comparison with the blend crystallized at atmospheric pressure suggests that the high pressure crystallization increases the compatibility of $\mathrm{PVF}_{2} / \mathrm{PMMA}$ during crystallization, although the crystallization curve of DTA was not compared because the cooling rate changed slightly in the crystallization process. Crystallinity of $\mathrm{PVF}_{2}$ in te blend does not seem to drop by high pressure crystallization considering that the intensity of the diffraction peak of $\mathrm{PVF}_{2}$ in the WAXD of Figure 5 does not decrease so much in the pressurecrystallized blend.

The change in melting temperature of $\mathrm{PVF}_{2}$ at atmospheric pressure with the weight fraction is shown in Figure 8. Two or more peaks of melting are observed in pure $\mathrm{PVF}_{2}$ crystallized under high pressure. The peak tempera- 


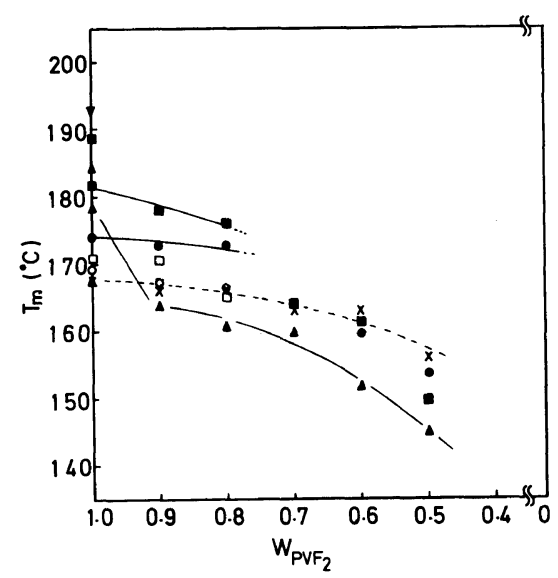

Figure 8. Weight fraction $\left(W_{\mathrm{PVF}_{2}}\right)$ dependence of peak melting temperature $\left(T_{\mathrm{m}}\right)$ of $\mathrm{PVF}_{2}$ in DSC curves at various crystallization pressures $\left(P_{\mathrm{c}}\right) . \cdots \times--, P_{\mathrm{c}}=$ $0.1 \mathrm{MPa} ; \bigcirc, P_{\mathrm{c}}=100 \mathrm{MPa}$ (high temperature peak); $\bigcirc$, $P_{\mathrm{c}}=100 \mathrm{MPa}$ (form II); $\square, P_{\mathrm{c}}=200 \mathrm{MPa}$ (form I); $\square$, $P_{\mathrm{c}}=200 \mathrm{MPa}$ (form II); $\boldsymbol{\Delta}, P_{\mathrm{c}}=300 \mathrm{MPa}$ (form I); $\boldsymbol{\nabla}$, $P_{\mathrm{c}}=300 \mathrm{MPa}$ (form I, ECC); $\triangle, P_{\mathrm{c}}=300 \mathrm{MPa}$ (low temperature peak).

ture and the peak height of the high temperature peak appeared in the melting of pure and blend samples crystallized at 100 and $200 \mathrm{MPa}$ decreases with decreasing $\mathrm{PVF}_{2}$ content. The peak disappeared below a $\mathrm{PVF}_{2}$ content of 0.7 . Considering that the form II content decreases with decreasing weight fraction of $\mathrm{PVF}_{2}$ in the blend sample crystallized at 100 and $200 \mathrm{MPa}$ as shown in the WAXD pattern in Figure 5, the low temperature peak is the melting of form II and form I but the form II content decreased and the form I content increased continuously with the decreasing $\mathrm{PVF}_{2}$ content. $T_{\mathrm{m}}$ of the $\mathrm{PVF}_{2}$ sample crystallized at $300 \mathrm{MPa}$ decreases drastically by blending only $10 \mathrm{wt} \%$ of PMMA. Furthermore, the decreasing rate of $T_{\mathrm{m}}$ with the weight fraction is the largest in the $\mathrm{PVF}_{2}$ of the blend crystallized at $300 \mathrm{MPa}$. The decrease in $T_{\mathrm{m}}$ of the blend crystallized at $300 \mathrm{MPa}$ also suggests the increased compatibility of the two polymers by high pressure crystallization. This is supported by the melting experiments under high pressure of the high pressure crystallized blend

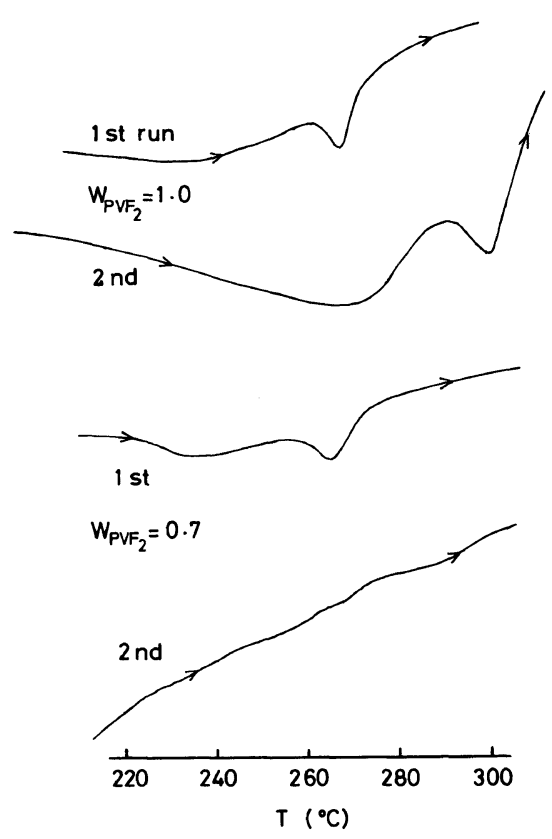

Figure 9. DTA curves of melting at $300 \mathrm{MPa}$ for samples of $W_{\mathrm{PVF}_{2}}=1.0$ and 0.7 . The 2 nd run was also performed after crystallization by cooling at $300 \mathrm{MPa}$.

sample. Figure 9 shows a comparison of the melting curve of DTA at $300 \mathrm{MPa}$ for the sample crystallized from the melt at $300 \mathrm{MPa}$ of $W_{\mathrm{PVF}_{2}}=1.0$ and $W_{\mathrm{PVF}_{2}}=0.7$. The DTA curve of melting for $W_{\mathrm{PVF}_{2}}=1.0$ is essentially the same as that of the DTA curve at atmospheric pressure. A broad low temperature peak and a high temperature peak which is due to the melting of ECC of form I is observed. However, the DTA curve in the meiting process for $W_{\mathrm{PVF}_{2}}=0.7$ shows no peaks up to $300^{\circ} \mathrm{C}$ at $300 \mathrm{MPa}$. This fact supports the idea that the compatibility of the two polymers increased under pressure, especially at $300 \mathrm{MPa}$.

All the $\mathrm{PVF}_{2}$ samples crystallized at $300 \mathrm{MPa}$ are form I as shown in Figure 5. Therefore, it is concluded that the high pressure crystallization of $\mathrm{PVF}_{2}$ in the blend with PMMA results in the formation of form I crystals with much lower melting temperature than form II. 
Acknowledgements. The authors wish to thank Showa Denko Co. for supplying the $\mathrm{PVF}_{2}$ (Foraflon) sample. They are also indebted to Miss M. Eguchi for the DSC measurements.

\section{REFERENCES}

1. W. W. Doll and J. B. Lando, J. Macromol. Sci., Phys., 2, 219 (1968).

2. R. Hasegawa, Y. Tanabe, M. Kobayashi, and H. Tadokoro, J. Polym. Sci., A-2, 8, 1073 (1970).

3. R. Hasegawa, M. Kobayashi, and H. Tadokoro, Polym. J., 3, 591 (1972).

4. M. Kobayashi, K. Tashiro, and H. Tadokoro, Macromolecules, 8, 158 (1975).

5. K. Sakaoku, S. Miyata, M. Misawa, and H. Hamashima, Rep. Prog. Polym. Phys. Jpn., 18, 259 (1975).
6. K. Matsushige and T. Takemura, J. Polym. Sci., Polym. Phys. Ed., 16, 921 (1978).

7. J. Scheinbeim, C. Nakafuku, B. A. Newman, and K. D. Pae, J. Appl. Phys., 50, 4399 (1979).

8. R. Hasegawa, Y. Takahashi, Y. Chatani, and H. Tadokoro, Polym. J., 3, 600 (1972).

9. W. W. Doll and J. B. Lando, J. Macromol. Sci., Phys., 4, 309 (1970).

10. T. Nishi and T. T. Wang, Macromolecules, 8, 909 (1975).

11. B. S. Morra and R. S. Stein, J. Polym. Sci., Polym. Phys. Ed., 20, 2243 (1982).

12. P. B. Rim and J. P. Runt, Macromolecules, 17, 1520 (1984).

13. B. S. Morra and R. S. Stein, Polym. Eng. Sci., 24, 311 (1984).

14. C. Nakafuku, Polymer, 22, 1963 (1981).

15. C. Leonard, J. L. Halary, L. Monnerie, D. Broussoux, B. Servet, and F. Micheron, Polym. Commun., 24, 110 (1983). 